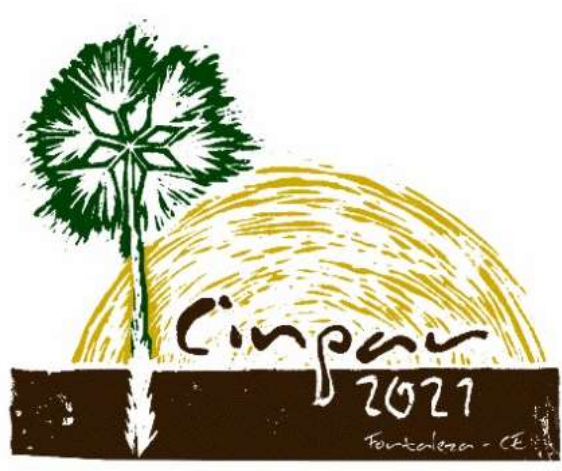

XVII Congresso Internacional sobre Patologia e Reabilitação das Construções

XVII Congreso Internacional sobre Patología y Rehabilitación de las Construcciones

XVII International Conference on Pathology and Constructions Rehabilitation

FORTALEZA (Brasil), 3 a 5 de junho de 2021 https://doi.org/10.4322/CINPAR.2021.034

\title{
RESTAURAÇÃO DO PATRIMÔNIO HISTÓRICO: obra da casa do Governador João Pessoa
}

\section{RESTORATION OF HISTORICAL HERITAGE: work done at the João Pessoa Governor's house}

\author{
Luanna Bernardo ${ }^{1}$, Cibelle Guimarães ${ }^{2}$, Valéria Vieira ${ }^{3}$ \\ ${ }^{1}$ Universidade Federal da Paraíba, João Pessoa, Brasil, luanna_bernardo@hotmail.com \\ ${ }^{2}$ Universidade Federal da Paraíba, João Pessoa, Brasil, cibelleguimaraes@yahoo.com.br \\ ${ }^{3}$ Centro Universitário de João Pessoa, João Pessoa, Brasil, valeria_vieira2014@hotmail.com
}

\begin{abstract}
Resumo: A restauração é uma das modalidades mais complexas da construção civil, pelo fato de ter que requalificar e beneficiar a edificação sem deixar de considerar as limitações e exigências necessárias. 0 presente trabalho tem como objetivo o estudo de caso de um patrimônio histórico tombado em 1980 pelo Instituto do Patrimônio Histórico e Artístico do Estado da Paraíba (IPHAEP). Trata-se de uma edificação construída em 1925, a qual denota má conservação uma vez que foi desabitada desde o início dos anos 2000 até 2018 , conhecida como a casa onde residiu o governador João Pessoa. Após muitos anos de tentativa, iniciou-se o processo de restauração e esse artigo mostra as principais manifestações patologicas encontradas e as soluções tomadas mantendo a estabilidade da edificação e as características da obra. Foram detectados problemas ocasionados pelo intemperismo e pela falta de manutenção do sobrado que danificaram bastante a integridade do mesmo. Dentre as principais manifestações patológicas observadas, encontram-se: infiltrações, madeiramento avariado por agentes biológicos, químicos e atmosféricos, manchas, eflorescências e desplacamento de tinta. No trabalho será possível analisar as etapas de restauração e o resultado do mesmo. Ratifica-se a importância que deve ser dada às edificações antigas, tendo convicção que houve um agravamento nas anomalias devido ao abandono e falta e manutenção periódica na casa. A obra não foi concluída devido a atrasos do processo construtivo, mas a pesquisa mostra até onde foi possível realizar o restauro.
\end{abstract}

Palavras-chave: Manifestações patológicas, patrimônio histórico, soluções, restauro.

Abstract: Restoration is one of the most complex modalities of civil construction, due to the fact that it has to requalify and benefit the building without neglecting the necessary limitations and requirements. The present work aims to study the case of a historic heritage registered in 1980 by the Institute of Historical and Artistic Heritage of the State of Paraíba (IPHAEP). It is a construction built in 1925, which shows poor conservation once it was uninhabited since the early 2000s until 2018, known as the house where Governor of João Pessoa resided. After many years of trying, the restoration process began and this article shows the main pathological manifestations found and the solutions taken while maintaining the stability of the building and the characteristics of the work. Where detected problems caused by weathering and the lack of maintenance of the house, which severely damaged its integrity. Among the main pathological manifestations observed, there were: infiltrations, wood damaged by biological, chemical and atmospheric agents, stains, efflorescence and paint stripping. At work it will be possible to analyze how the restoration 
steps and the result of the same. The importance that should be given to old buildings is ratified, with the conviction that there was a worsening of anomalies due to abandonment and lack and periodic maintenance in the house. The work was not completed due to delays in the construction process, but the research shows how far it was possible to carry out the restoration.

Keywords: Pathological manifestations, historical heritage, solutions, restoration.

\section{Introdução}

Uma obra é considerada tombada quando o poder público considera a mesma importante e quer efetivar a proteção do patrimônio cultural e natural do país. Tombamento é ato administrativo posto ao dispor do Poder Público para a efetiva proteção do patrimônio cultural e natural do país, cujo efeito precípuo é transformar em interesse jurídico o valor contido na coisa (BULOS, 2010).

Por possui valor histórico, o patrimônio que será estudado a seguir, foi tombado pelo Instituto Histórico e Artístico do Estado da Paraíba (IPHAEP). O estudo tratará da recuperação da casa em que residiu o $15^{\circ}$ governador da Paraíba, João Pessoa, que dá nome à cidade. Uma obra tombada deve manter as características iniciais da edificação, entretanto o intenso desgaste apresentado devido ao tempo, já que a residência foi construída desde 1929, e à falta de manutenção, gerou dificuldades, passando a exigir bem mais do que o usual da equipe envolvida.

Souza e Ripper (1998) explicam que os problemas deflagrados durante o ciclo de vida de edificação podem ser diversos, causados tanto por envelhecimento natural dos materiais quanto por acidentes ocorridos durante o seu uso.

O interesse nesse estudo veio a partir da visão em obra de como é fascinante vislumbrar como se pode reerguer uma obra que estava tão degradada e como a engenharia pode ser abrangente e importante, mantendo patrimônios históricos conservados de forma autêntica e surpreendente.

\section{Caracterização da casa de João Pessoa}

O edifício analisado neste trabalho é denominado casa onde viveu o governador João Pessoa e está localizado na Praça da Independência $n^{\circ} 92$ no município de João Pessoa, Paraíba. De acordo com o acervo patrimonial, foi construído pelo engenheiro Soutto Barcellos em 1925. O presidente João Pessoa morou no sobrado até 1930, ano de seu assassinato. Após o incidente, o imóvel foi vendido até chegar ao controle estadual, onde foram instaladas instituições públicas, o que ocasionou algumas mudanças em seu interior e má manutenção do imóvel. No início dos anos 2000, a casa estava desabitada e abandonada e em 2013, foi proposto a adaptação do ambiente ao museu público, restauração que só começou em setembro de 2018, sendo finalizada em fevereiro de 2021.

A residência apresenta características próprias da época em que foi construída e graças a registros do Instituto do Patrimônio Histórico e Artístico do Estado da Paraíba (IPHAEP), foi possível se ter mais detalhes da obra inicial, o que contribuiu para restauração. 


\section{Principais manifestações patológicas encontradas}

\subsection{Manifestações patológicas na Madeira}

A maior parte da casa foi construída em madeira do tipo Massaranduba e pode-se ver que, devido ao abandono da mesma, o intemperismo e a chegadas de cupins ocasionou os problemas patológicos graves encontrados antes do início da restauração. Isso se deve à degradação do material devido à exposição biológica a insetos e à umidade presente no ambiente.

A NBR 7190: 1997 apresenta que "os componentes da estrutura de madeira podem enfrentar vários graus de riscos de degradação biológica devido à presença de organismos xilose no local e às condições ambientais que podem conduzir a tais ataques." Um exemplo disso é o telhado e o piso como mostrado nas Figuras 1 e 2.

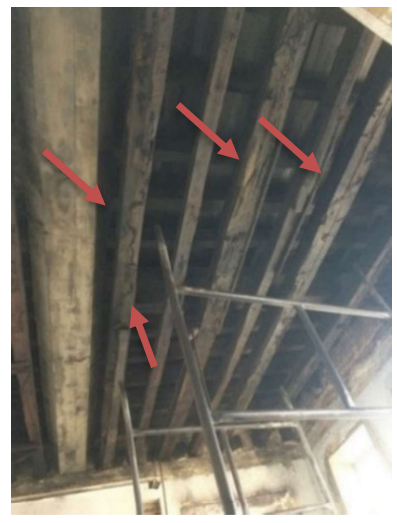

Figura 1 - Telhado antes da restauração

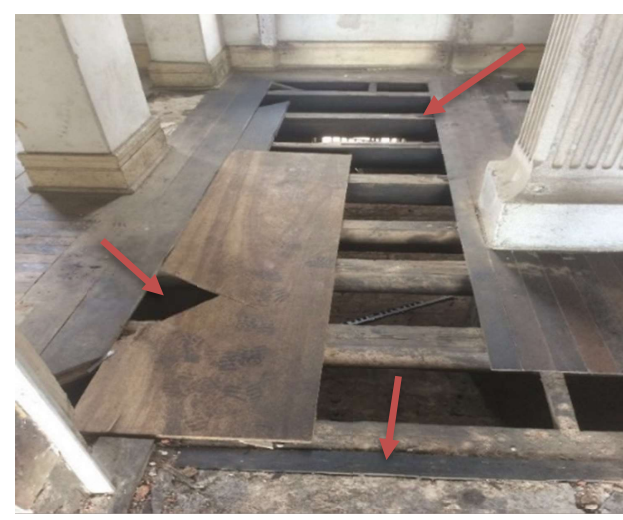

Figura 2 - Piso antes da restauração

Tanto o piso quanto o telhado tiveram que passar por uma perícia para que fosse identificado a gravidade dos danos nas peças. Após esse processo o responsável técnico da obra optou pela retirada delas e aplicação de cupinicida em duas camadas. As peças que se encontravam em bom estado foram lixadas e restauradas, as outras foram substituídas por madeiramento do mesmo tipo da original, Massaranduba.

Além do desgaste no piso e no teclado os cupins ocasionaram dados estruturais, trazendo um grande desgaste nos caibros, ripas, e linhas como mostrados nas Figuras 3 e 4.

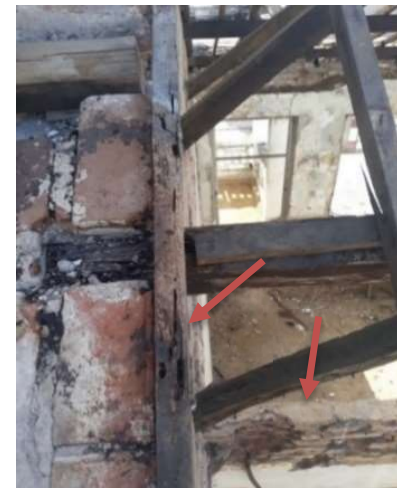

Figura 3 - Madeira descascada

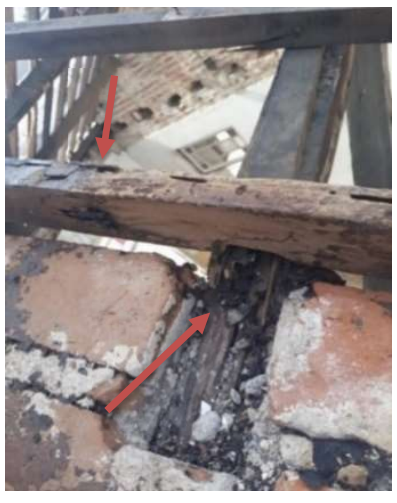

Figura 4 - Madeira avariada 
Segundo Braga (sd, p. 7), "a técnica da conservação deve ser definida a partir de análises criteriosas das causas dos degrados". Então mesmo que se exista a importância de manter a originalidade das peças, o parecer técnico é o fator mais importante para decidir se serão trocadas ou não. Na residência, foi preciso analisar o fator estrutural, sendo necessário a substituição de boa parte das peças, para garantir a segurança da obra.

A escada que permitia o acesso do térreo ao primeiro pavimento visualmente não apresentava grandes problemas, mas após uma perícia foi constatado uma quantidade considerável de insetos na parte interna da mesma, demonstrado na Figura 5 a seguir.

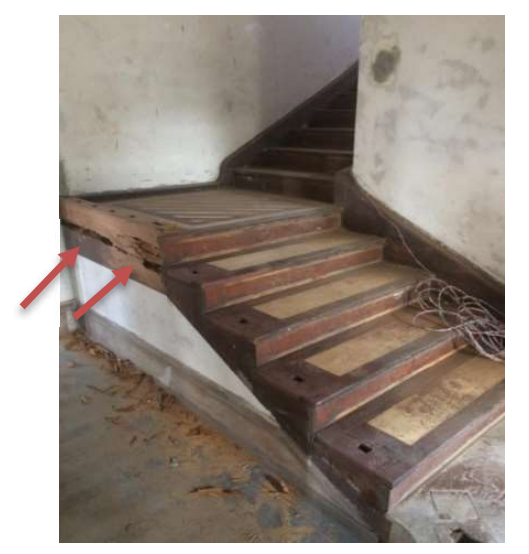

Figura 5 - Cupins na lateral da escada

\subsection{Manifestações patológicas na pintura}

Sabe-se que a pintura foi realizada por meio de tinta lavável, contudo não se tem registros da coloração inicial da mesma, sendo necessário um estudo preliminar com a raspagem das camadas de tinta para analisa-las e chegar a tonalidade inicial da pintura, garantindo assim a originalidade da obra. É possivel identificar que, por não haver cuidados necessarios, a cor foi tornando-se opaca em virtude de fatores quimicos e biologicos.

A Figura 6 a seguir, demonstra o estudo das camadas, feito para decidir qual tonalidade seria viavel para garantir a restauração adequada aos padrões iniciais da obra, optando pelo branco gelo com detalhes na tonalidade camurça e definindo o uso de uma tinta a oleo para que pudesse resistir mais ao intemperismo.

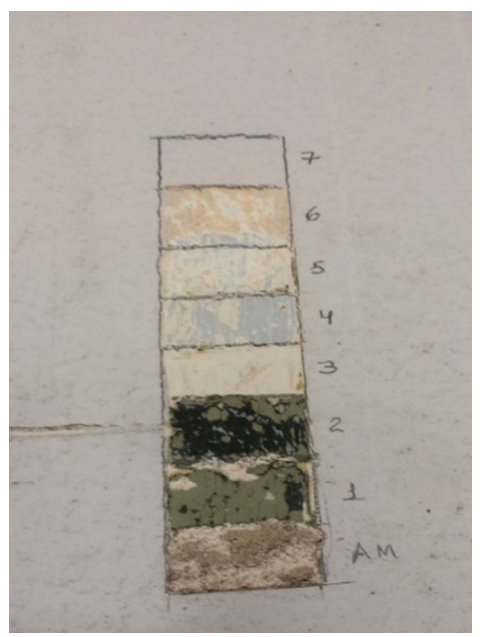

Figura 6 - Estudo de camadas de pintura 


\subsection{1 - Parede Internas}

Devido a umidade exitente dentro da residência que passou um tempo fechada, bem como a falta de reparos realizados ao longo dos anos, alguns problemas surgiram, dentre eles: bolor, eflorescência e absorção capilar. A figura 7 apresenta o bolor, colônia de fungos, no reboco em uma área úmida e que não recebe a luz solar com frequência. $O$ resultado promovido pela ação desse fungo é a queda da pintura.

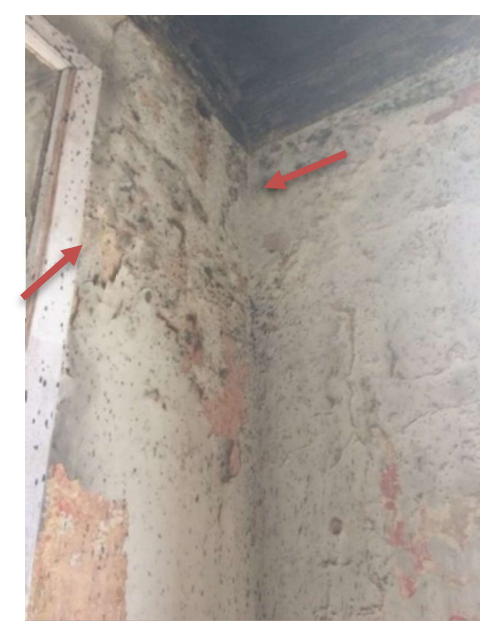

Figura 7 - Fungos no reboco

A eflorescência, manchas brancas ao longo da alvenaria, também foi encontrada na residência, o fato ocorreu devido a reações provocadas pela umidade. Além disso, também pode-se observar a perda de coesão do reboco e a redução da aderência da pintura no mesmo devido a presença da absorção capilar que ocorre quando a água presente no solo entra em contato com a alvenaria. A seguir encontram-se as Figuras 8 e 9 representando as manifestações ditas acima.

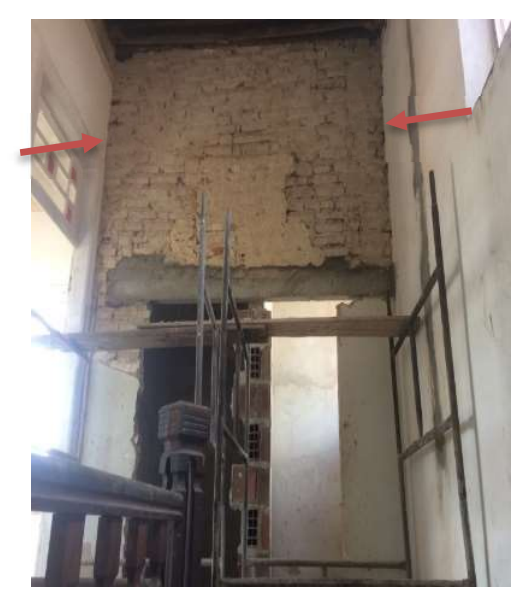

Figura 8 - Degradação do reboco

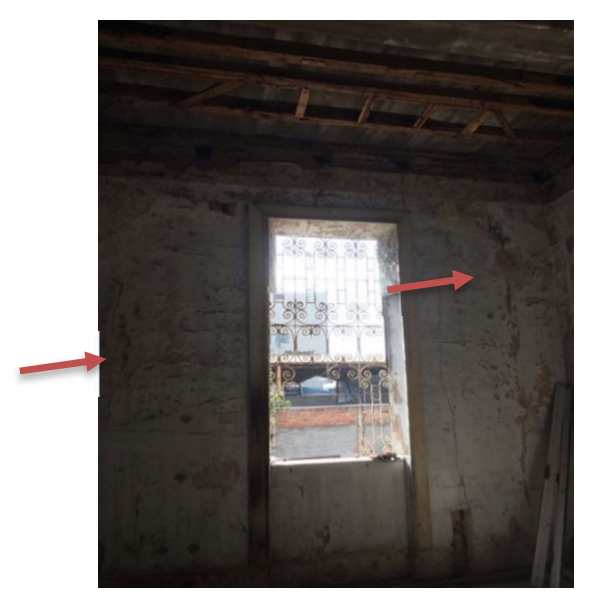

Figura 9 - Absorção capilar no reboco

Assim, para garantir que a tinta tivesse uma boa fixação, inicialmente foi necessário que tivesse sido retirada a camada que estava desplacando, após isso ocorreu uma raspagem manual em todas as paredes da residência deixando-as preparadas para receber a massa acrílica e a pintura de forma adequada. Em seguida, realizou-se o nivelamento da parede com uma massa acrílica e, logo após, foi possível a aplicação da tinta. Como a umidade ocasionou problemas na alvenaria, escolheu-se uma tinta a óleo. Abaixo encontra-se a Figura 10 onde demonstra a alvenaria após aplicação da massa acrílica. 


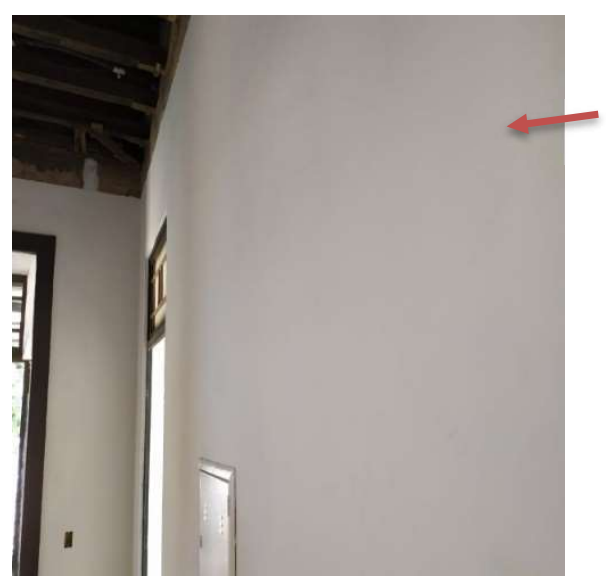

Figura 10 - Aplicação de massa acrilica na alvenaria

\subsection{2 - Parede Externas}

A parede externa, por estar mais plenamente exposta as intempéries, acaba sofrendo mais desgaste. Assim, além de bolores, têm-se também fungos que alteram a tonalidade da parede deixando-a mais escura e com aspecto de suja. A Figura 10 abaixo demonstra a vista externa da casa.

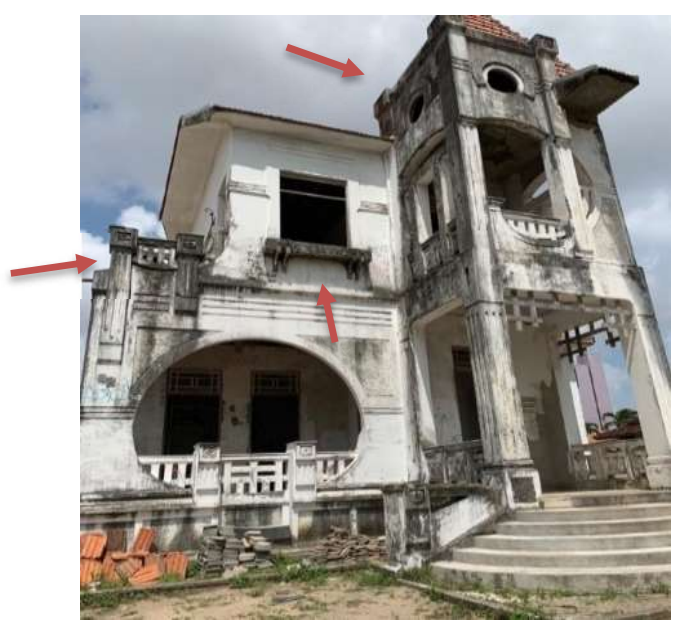

Figura 10 - Vista externa da casa

Para início do processo de restauração, além do lixamento foi necessário um jateamento para limpar com mais facilidade as paredes externas. Após isso foi realizada uma aplicação de massa acrílica com lixamento para nivelar a massa e realizar a pintura. A tonalidade escolhida para a pintura da alvenaria externa foi branco gelo com detalhes no tom camurça, buscando aproximação com as características da casa original, mostrados nas Figuras 11 e 12. 


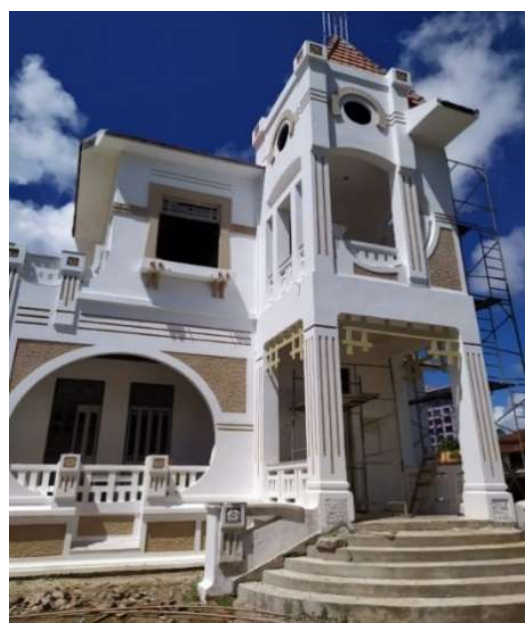

Figura 11 - Aplicação de massa acrilica nas paredes externas

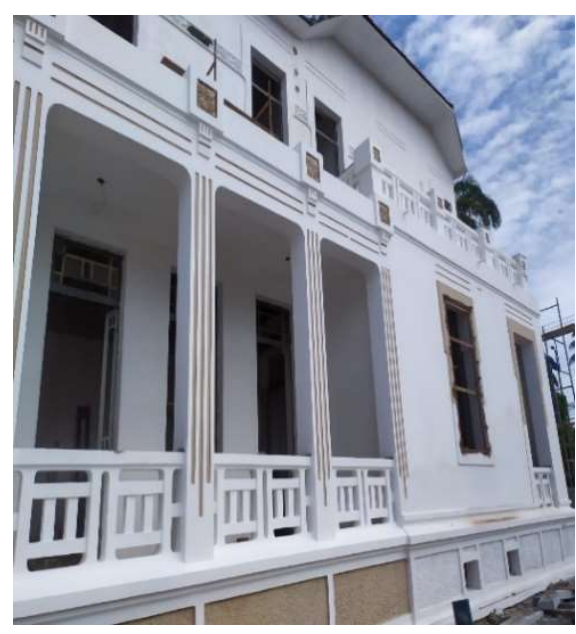

Figura 12 - Vista lateral da casa

\section{Conclusões}

Assim como a maioria das obras que foram tombadas para restauração, os maiores danos foram ocasionados pelo desgaste do tempo e pela má conservação, já que a casa foi abandonada e negligenciada por muitos anos. Pode-se analisar várias manifestações patológicas e pontos de desgaste, vendo que os maiores problemas foram com a infiltrações, madeiramento da coberta, piso e escada avariado por agentes biológicos, químicos e atmosféricos, manchas, eflorescências e desplacamento de tinta.

Esse trabalho mostra a importância do cuidado com obras tombadas, já que são parte da história. Engenheiro e arquitetos tem um papel muito importante em todo processo de restauração, já que com o parecer técnico é possível trabalhar e restaurar as obras de forma correta e segura. E o cuidado prévio contribui para minimizar as anomalias que possam advir à estrutura para proporcioná-la maior conforto visual, vida útil e segurança. É importante ressaltar que na obra foram feitos reparos convencionais e que as manifestações patológicas podem reaparecer.

\section{Agradecimentos}

Agredecimento especial à Superintendência de Obras do Plano de Desenvolvimento do Estado (SUPLAN) responsável pela obra de restauração do novo Museu João Pessoa.

\section{Referências Bibliográficas}

ASSOCIAÇÃO BRASILEIRA DE NORMAS TÉCNICAS (ABNT). NBR-15575: Edificações habitacionais Desempenho. São Paulo, 2013.

ASSOCIAÇÃO BRASILEIRA DE NORMAS TÉCNICAS. NBR 7190: Projeto de estruturas de madeira. Rio de Janeiro, 1997.

BOLINA, F.L; TUTIKIAN, B. F.; HELENE, P. Patologia de estruturas. Editora Oficina de Textos, 2019. 320p.

BULOS, Uadi Lammêgo. Curso de Direito Constitucional. 5. Ed. São Paulo: Saraiva, 2010.

BRAGA, Márcia. Conservação e restauro - Arquitetura (sd). Disponível em: http://marciabraga.arq.br/voi/images/stories/pdf/MarciaBraga arq bras.pdf. Acesso em: 15 jan. 2021.

CARTA de Atenas. Restauração, [S. I.], p. 1-6, out. 1931. Disponível em: http://portal.iphan.gov.br/uploads/ckfinder/arquivos/Carta\%20de\%20Atenas\%201931.pdf. Acesso em: 2 fev. 2021. 
MEMORIA JOÃO PESSOA. Informatizando a história do nosso patrimônio. Nov. 2013. Disponível em: <http://www.memoriajoaopessoa.com.br/acervopatrimonial/137.pdf>. Acesso em: 06 jan. 2021.

SOUZA, V.C.M; RIPPER, T. Patologia e reforço de concreto. São Paulo: Editora PINI, 1998. 262p 